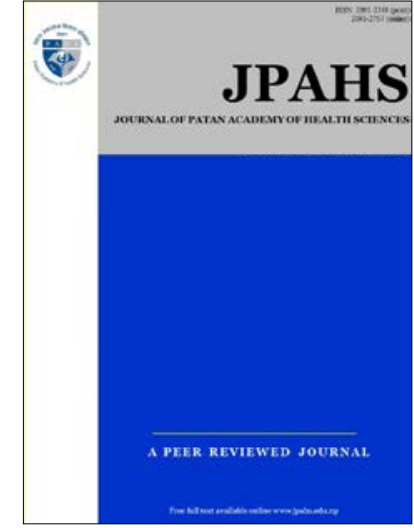

ISSN: 2091-2749 (Print) 2091-2757 (Online)

\section{Acknowledgement: for the reviewers of Journal of Patan Academy of Health Sciences}

Jay Shah $\mathrm{E}$

Chief editor, Journal of Patan Academy of Health Sciences (JPAHS), Patan Academy of Health Sciences (PAHS), Lalitpur, Kathmandu, Nepal

DOI: https://doi.org/10.3126/jpahs.v7i3.33928

We from the editorial team greatly appreciate the reviewers for your time and expertise to the journal's rigorous editorial process, regardless of whether the papers are finally published or not in the JPAHS- Journal of Patan Academy of Health Sciences. We would like to express our sincere gratitude to all the reviewers for your generous contribution.

The JPAHS published 70 articles in three issues during the year 2020. In 2020, the time for submissions to acceptance was average $33.1 \mathrm{~d}$ (range 1-239, median $22 \mathrm{~d}$ ), from acceptance to publication the was $14.4 \mathrm{~d}$ (range 1 to 194, median $21 \mathrm{~d}$ ). In 2019, the time for submissions to acceptance was an average of $142.6 \mathrm{~d}$ (range 13-540, median $52.5 \mathrm{~d}$ ), from acceptance to publication the was $50.1 \mathrm{~d}$ (range 3 to 148 , median $35.5 \mathrm{~d}$ ). From 2020 JPAHS has been publishing three issues annually from the earlier two issues annually. Beginning from 2014, the journal has published a total of 232 articles.

We wish for your continuous support.

Dr. Prof. Jay Shah

The Chief Editor

Journal of Patan Academy of Health Sciences (JPAHS)

Journal of Patan Academy of Health Sciences, Lalitpur, Kathmandu, Nepal

Email: editor.jpahs@pahs.edu.np,drjaywufei@gmail.com, jayshah@pahs.edu.np

December 2020 
National Reviewers

1. Dr. Ajay K Mishra, Professor, Janaki Medical College, Janakpur, Nepal.

2. Dr. Ajit Nepal, Professor, Department of Otorhinolaryngology, Patan Hospital, School of Medicine, Patan Academy of Health Sciences, Lalitpur, Kathmandu, Nepal.

3. Dr. Amit Joshi, Professor, Department of Orthopaedics, KIST Medical College, Imadole, Lalitpur, Kathmandu, Nepal.

4. Dr. Amit Mani Upadhyay, Senior Consultant, Department of Urology, Kathmandu Model Hospital, Kathmandu, Nepal.

5. Dr. Anil Shrestha, Assistant Professor, Department of Anaesthesiology, Patan Hospital, School of Medicine, Patan Academy of Health Sciences, Lalitpur, Kathmandu, Nepal.

6. Dr. Arbin Joshi, Senior Consultant, Department of Surgery, B\&B Hospital, Kathmandu, Nepal.

7. Dr. Arun Neopane, Professor, Department of Paediatrics, Shree Birendra Hospital, Nepalese Army Institute of Health Sciences, Sano Bharyang, Kathmandu, Nepal.

8. Dr. Ashis Shrestha, Assistant Professor, Department of General Practice and Family Medicine, Patan Hospital, School of Medicine, Patan Academy of Health Sciences, Lalitpur, Kathmandu,

9. Dr. Balakrishnan M Acharya, Professor, Department of Orthopaedics and Trauma Surgery, Patan Hospital, School of Medicine, Patan Academy of Health Sciences, Lalitpur, Kathmandu, Nepal.

10. Dr. Bharat Kumar Yadav, Professor, Department of General Practice and Emergency Medicine, School of Public Health, Patan Academy of Health Sciences, Lalitpur, Kathmandu, Nepal.

11. Dr. Bidur Gyawali, Assistant Professor, Department of Department of Orthopaedics and Trauma Surgery, Patan Hospital, School of Medicine, Patan Academy of Health Sciences, Lalitpur, Kathmandu, Nepal.

12. Dr. Bijay Thapa, Assistant Professor, Department of Community Medicine and Tropical Diseases, School of Public Health, Patan Academy of Health Sciences, Lalitpur, Kathmandu, Nepal.

13. Dr. Bikal Ghimire, Assoc. Prof. G.I \& Hepatobiliary Surgery, Institute of Medicine, Tribhuvan University Teaching Hospital, Kathmandu, Nepal.

14. Dr. Bikash Desar, Assistant Professor, Department of Dentistry, Patan Hospital, School of Medicine, Patan Academy of Health Sciences, Lalitpur, Kathmandu, Nepal.

15. Dr. Binita Pradhan, Associate Professor, Department of Obstetrics and Gynaecology, Patan Hospital, School of Medicine, Patan Academy of Health Sciences, Nepal.

16. Dr. Bishnu Prasad Sharma, Associate Professor, Department of Dentistry, Patan Hospital, School of Medicine, Patan Academy of Health Sciences, Lalitpur, Kathmandu, Nepal.

17. Dr. Buddhi Prasad Paudel, Professor, Department of Internal Medicine, Patan Hospital, School of Medicine, Patan Academy of Health Sciences, Nepal.

18. Dr. Ganesh Dangal, Professor, Department of Gynaecology and Obstetrics, Kathmandu Model Hospital, Kathmandu, Nepal.

19. Dr. Gehanath Baral, Professor, Department of Gynaecology and Obstetrics, Nobel Medical College, Biratnagar, Morang, Nepal.

20. Dr. Imran Ansari, Professor, Department of Paediatrics, Patan Hospital, School of Medicine, Patan Academy of Health Sciences, Lalitpur, Kathmandu, Nepal.

21. Ms. Ira Shrestha, Associate Professor, Department of Physiology, School of Medicine, Patan Academy of Health Sciences, Lalitpur, Kathmandu, Nepal.

22. Dr. Jayant Shah, Lecturer, Department of Surgery, Institute of Medicine, Tribhuvan University Teaching Hospital, Kathmandu, Nepal.

23. Dr. Kapendra Shekhar Amatya, Senior Consultant, Department of Surgical Oncology, Nepal Cancer Hospital \& Research Centre, Lalitpur, Kathmandu, Nepal.

24. Dr. Kishor Manandhar, Associate Professor, Department of Surgery, Bir Hospital, National Academy of Health Sciences, Kathmandu, Nepal.

25. Ms. Lalita Rai, Associate Professor, Maharajgunj Nursing Campus, Tribhuvan University Institute of Medicine, Kathmandu, Nepal.

26. Dr. Laxmi RC, Associate professor, Department of Obstetrics and Gynaecology, Patan Hospital, School of Medicine, Patan Academy of Health Sciences, Nepal.

27. Mr. Madhusudan Subdi, Professor, School of Public Health, Patan Academy of Health Sciences, Lalitpur, Kathmandu, Nepal.

28. Ms. Mili Joshi, Assistant Professor, Department of Pharmacology, School of Medicine, Patan Academy of Health Sciences, Lalitpur, Kathmandu, Nepal. 
29. Dr. Nabees MS Pradhan, Professor, Department of Orthopaedics and Trauma Surgery, Patan Hospital, School of Medicine, Patan Academy of Health Sciences, Lalitpur, Kathmandu, Nepal.

30. Dr. Narbada Thapa, Professor (Retired), College of Nursing, Nepalese Army Institute of Health Sciences, Sano Bharyang, Kathmandu, Nepal.

31. Dr. Paban Sharma, Professor, Department of Obstetrics and Gynaecology, Patan Hospital, School of Medicine, Patan Academy of Health Sciences, Lalitpur, Kathmandu, Nepal.

32. Dr. Paleswan Joshi Lakhey, G.I \& Hepatobiliary Surgery, Institute of Medicine, Tribhuvan University Teaching Hospital, Kathmandu, Nepal.

33. Dr. Pwan Kumar Hamal, Assist Prof., Department of Anaesthesia, National Academy of Medical Sciences, Kathmandu, Nepal.

34. Dr. Pawan Sharma, Lecturer, Department of Psychiatry, Patan Hospital, School of Medicine, Patan Academy of Health Sciences, Lalitpur, Kathmandu, Nepal.

35. Dr. Piyush Rajbhandari, Assistant Professor, Department of Pathology and Laboratory Medicine, Patan Hospital, School of Medicine, Patan Academy of Health Sciences, Lalitpur, Kathmandu, Nepal.

36. Dr. Pramod Devkota, Associate Professor, Department of Orthopaedics and Trauma Surgery, Patan Hospital, School of Medicine, Patan Academy of Health Sciences, Lalitpur, Kathmandu, Nepal.

37. Dr. Prashant Shrestha, Assistant Professor, Department of Obstetrics and Gynaecology, Patan Hospital, School of Medicine, Patan Academy of Health Sciences, Nepal.

38. Dr. Prerana Kansakar, Assistant Professor, Department of Paediatrics, Patan Hospital, School of Medicine, Patan Academy of Health Sciences, Lalitpur, Kathmandu, Nepal.

39. Dr. Priscilla Samson, Associate Professor, Lalitpur Nursing Campus, School of Nursing and Midwifery, Patan Academy of Health Sciences, Lalitpur, Kathmandu, Nepal.

40. Dr. Pukar Maskey, Professor, Department of Surgery/Urology, Patan Hospital, Patan Academy of Health Sciences, Lalitpur, Kathmandu, Nepal.

41. Dr. Ram Naresh Pandit, Sr. Consultant, Janakpur Provincial Hospital, Dhanusha, Nepal.

42. Dr. Ranjana Sharma, Assistant Professor, Department of Ophthalmology, Patan Hospital, School of Medicine, Patan Academy of Health Sciences, Lalitpur, Kathmandu, Nepal.

43. Dr. Reetu Baral, Professor, Department of Pathology, Nobel Medical College, Biratnagar, Morang, Nepal.

44. Dr. Reshu Agrawal Sagtani, Assistant Professor, School of Public Health, Patan Academy of Health Sciences, Lalitpur, Kathmandu, Nepal.

45. Dr. Rojan Tamrakar, Consultant Surgeon, Department of Orthopaedics, National Academy of Medical Sciences, Kathmandu, Nepal.

46. Dr. Roshana Shrestha, Associate Professor, Department of General Practice and Emergency Medicine, Kathmandu, University, Nepal.

47. Dr. Rupesh Mukhiya, Associate Professor, Department of Surgery, KIST Medical College, Imadole, Lalitpur, Kathmandu, Nepal.

48. Dr. Rupesh Gami, Consultant, Department of Anaesthesia, Koshi Hospital, Biratnagar, Nepal.

49. Dr. Samita Acharya, Associate Professor, Department of General Practice and Emergency Medicine, Patan Hospital, School of Medicine, Patan Academy of Health Sciences, Lalitpur, Kathmandu, Nepal.

50. Dr. Sanjaya Paudyal, Professor, Department of Surgery, Patan Hospital, School of Medicine, Patan Academy of Health Sciences, Lalitpur, Kathmandu, Nepal.

51. Dr. Sarala Shrestha, Professor, College of Nursing, Nepalese Army Institute of Health Sciences, Sano Bharyang, Kathmandu, Nepal.

52. Dr. Shambhu K Upadhyay, Professor, School of Public Health, Patan Academy of Health Sciences, Lalitpur, Kathmandu, Nepal.

53. Dr. Sharada Duwal, Associate Professor, Department of Obstetrics and Gynaecology, Patan Hospital, School of Medicine, Patan Academy of Health Sciences, Nepal.

54. Mr. Shital Bhandary, Associate Professor, School of Public Health, Patan Academy of Health Sciences, Lalitpur, Kathmandu, Nepal.

55. Dr. Shiva Raj KC, Associate Professor, Department of Pathology and Laboratory Medicine, Patan Hospital, School of Medicine, Patan Academy of Health Sciences, Lalitpur, Kathmandu, Nepal.

56. Dr. Shreekrishna Maharjan, Assistant Prof. Department of Biochemistry, School of Medicine, Patan Academy of Health Sciences, Lalitpur, Kathmandu, Nepal.

57. Dr. Shrijana Shrestha, Professor, Department of Paediatrics, Patan Hospital, School of Medicine, Patan Academy of Health Sciences, Lalitpur, Kathmandu, Nepal.

58. Dr. Suchita Joshi, Associate Professor, Department of Paediatrics, Patan Hospital, School of Medicine, Patan Academy of Health Sciences, Lalitpur, Kathmandu, Nepal. 
59. Dr. Sulochana Joshi, Assistant Professor, Department of Psychiatry, Patan Hospital, School of Medicine, Patan Academy of Health Sciences, Lalitpur, Kathmandu, Nepal.

60. Dr. Sumana Bajracharya, Assistant Professor, Department of General Practice and Emergency Medicine, Patan Hospital, School of Medicine, Patan Academy of Health Sciences, Lalitpur, Kathmandu, Nepal.

61. Dr. Sunita Maleku Amatya, Senior Consultant, Department of Anaesthesiology, Nepal Cancer Hospital \& Research Centre, Lalitpur, Kathmandu, Nepal.

62. Dr. Surendra Shah, Assistant Professor, Department of Surgery, Patan Hospital, School of Medicine, Patan Academy of Health Sciences, Lalitpur, Kathmandu, Nepal.

63. Dr. Tripti Shakya, Assistant Professor, Department of Anatomy, School of Medicine, Patan Academy of Health Sciences, Lalitpur, Kathmandu, Nepal.

64. Dr. Vivek Todi, Department of Paediatrics, Norvic International Hospital, Kathmandu, Nepal.

65. Dr. Yagya Raj Pokharel, Assistant Professor, Department of General Practice and Emergency Medicine, Patan Hospital, School of Medicine, Patan Academy of Health Sciences, Lalitpur, Kathmandu, Nepal.

66. Dr. Yogendra Amatya, Assistant Professor, Department of General Practice and Emergency Medicine, Patan Hospital, School of Medicine, Patan Academy of Health Sciences, Lalitpur, Kathmandu, Nepal.

International Reviewers

1. Dr. Aradhana Michael (PhD), Nursing, India.

2. Dr. Shiv Chandra Mathur, Preventive and Social Medicine, India.

3. Dr. Bertram Sah, Radiology and Nuclear Medicine, Germany.

4. Dr. Birendra Sah, GI Surgery, China.

5. Dr. Dipesh Kumar Yadav, Surgery Liver Transplant, China.

6. Dr. Dipesh Maskey, Medicine Pulmonogy, Bahrain

7. Dr. Fredrik Theodoor Boseman, Pathology, Netherlands.

8. Dr. Jiao Fuyong, Paediatrics, China.

9. Dr. Mohammad Azizur Rahaman, Medicne, Bangladesh.

10. Dr. Paul Worley, General Practice and Family Medicine, Australia.

11. Dr. Ram Krishna Dulal, Public Health, Germany.

12. Dr. Rose House, Medicine, USA.

13. Dr. Satish k Shukla, Surgery, India

14. Dr. Supat Sinawat, Thailand.

15. Dr. Wang Zhen, GI Surgery, China.

16. Dr. Yang Yan (PhD), Nursing, China.

17. Dr. Zhong Ming, GI Surgery Colorectal, China. 